\title{
BMJ Open A five-year trend in pre-eclampsia admission and factors associated with inpatient eclampsia: a retrospective study from a resource-limited hospital in northeast Ethiopia
}

Kenean Getaneh Tlaye (D) , ${ }^{1}$ Melese Linger Endalifer, ${ }^{2}$ Mikiyas Amare Getu, ${ }^{1}$ Addisu Getie Nigatu, ${ }^{1}$ Eleni Tesfaye Kebede ${ }^{3}$

To cite: Tlaye KG, Endalifer ML, Getu MA, et al. A five-year trend in pre-eclampsia admission and factors associated with inpatient eclampsia: a retrospective study from a resource-limited hospital in northeast Ethiopia. BMJ Open 2021;11:e040594. doi:10.1136/ bmjopen-2020-040594

- Prepublication history for this paper is available online. To view these files, please visit the journal online (http://dx.doi. org/10.1136/bmjopen-2020040594).

Received 18 May 2020 Revised 08 January 2021 Accepted 23 January 2021

Check for updates

(C) Author(s) (or their employer(s)) 2021. Re-use permitted under CC BY-NC. No commercial re-use. See rights and permissions. Published by BMJ.

${ }^{1}$ Department of Nursing, College of Health Science, Woldia University, Woldia, Ethiopia ${ }^{2}$ Department of Midwifery, College of Health Science, Woldia University, Woldia, Ethiopia

${ }^{3}$ Department of Midwifery, College of Health Science, Selale University, Fiche, Ethiopia

Correspondence to Mr Kenean Getaneh Tlaye; kenan34@wldu.edu.et

\section{ABSTRACT}

Objective To investigate the 5-year trend of preeclampsia admission, magnitude and factor associated with inpatient eclampsia among deliveries involving pre-eclampsia which have been attended at one of the resource-limited public hospitals in northeast Ethiopia. Design Retrospective medical record review study. Setting Woldia General Hospital Medical archive, Woldia town, Ethiopia.

Participants All antenatal admission and deliveries involving pre-eclampsia attended from 2011 to 2016 at the hospital were included in the review.

Primary and secondary outcome measures Trend of pre-eclampsia admission was determined using nonparametric Mann-Kendall correlation. Case management, clinical and patient-related factors were tested for possible association with the development of inpatient eclampsia using binary logistic regression. P value less than 0.05 considered significant.

Result Across the 5-year period, there were 8764 deliveries attended at the hospital's labour and delivery ward, of them $241(2.76 \%)$ were co-diagnosed with preeclampsia. The trend showed marginal decrement through years (tau-b correlation coefficient $(T b)=-0.4, p=0.035$ ) with the highest caseload (4.4\%) observed on year $2013 / 2014$. The rate of inpatient eclampsia was 19.6 per 10000 births and the likelihood of its occurrence among pre-eclamptic women was $7.1 \%(95 \% \mathrm{Cl} 2.7 \%$ to $11.5 \%)$. In multivariate analysis, being multigravida (adjusted OR (AOR) $0.154,95 \% \mathrm{Cl} 0.029$ to 0.831 ) and spontaneous onset of labour (AOR $5.628,95 \% \mathrm{Cl} 1.1247$ to 9.401 ) were associated with inpatient eclampsia.

Conclusion In the study setting, the overall magnitude of pre-eclampsia admission was comparable with the global average, but its yearly trend showed marginal decrement from 2011 to 2016. High rate of inpatient eclampsia might indicate undertreatment which alarms further study and/or corrective measures. Waiting for spontaneous onset of labour could increase the risk of developing inpatient eclampsia whereas neither type of anticonvulsant nor duration of its usage has made significant association.

\section{Strengths and limitations of this study}

- The study assessed new variables such as time lapse to initiate different interventions.

- The study has pointed out a possible difference in trend of pre-eclampsia admission and patient prognosis in a resource-limited health facility.

- The chronological nature of data extraction from admission to discharge allowed us to take the magnitude of inpatient eclampsia as its incidence.

- Some important clinical factors of pre-eclampsia such as chronic kidney disease, antiphospholipid syndrome, systemic lupus erythematosus and type of conception were not assessed in the study.

- Comparison between admitted non-pre-eclamptic women with pre-eclamptic counterparts on common parameters could give better reference for the findings.

\section{BACKGROUND}

Pre-eclampsia is part of a pregnancy-specific syndrome defined by the American College of Obstetricians and Gynecologists as a multisystem progressive disorder characterised by the new onset of hypertension and proteinuria, or of hypertension and significant end-organ dysfunction with or without proteinuria, in the last half of pregnancy or post partum. ${ }^{1}$ It is estimated that $4.6 \%$ (95\% CI $2.7 \%$ to $8.2 \%)$ of all deliveries are from pre-eclampsia women globally. ${ }^{2}$ The disorder has been identified as the leading reason for maternal admission to the intensive care unit during the puerperal period. ${ }^{3}$ Trends of population-based prevalence and hospital admission due to pre-eclampsia has been reported differently among studies. For instance, in a report in 2014, almost $5 \%$ of all inpatient deliveries in the USA involved pre-eclampsia/eclampsia which was a $21 \%$ 
increase from 2005. ${ }^{4}$ Similarly, a study finding from Cameroon pointed out the overall increasing trend of intensive care unit admission due to pre-eclampsia. ${ }^{5}$ Such studies articulated the increasing trend of pre-eclampsia with increased number of pregnancies among women of advanced maternal age and the obesity epidemic. To the contrary, a finding from a large-scale international comparative study showed the rate of pregnancy hypertension and pre-eclampsia decreased in northern Europe and Australia from 1997 to $2007 .^{6}$

Though more than 25000 researches have been done on pre-eclampsia so far, further studies are still demanding on its aetiology, predictive biomarkers, longterm cardiometabolic complications as well as effective management options. ${ }^{7}$ Undoubtably, researches aiming to fill this gaps need to be conducted at high quality by effectively selecting, grouping and recruiting large sample size, use of advanced technology and sophisticated multivariable model analysis. In the meantime, epidemiological studies on trend of admission, clinical care auditing and factors related with adverse patient outcome in resource limited areas, where standardised patient care is usually limited, are equally important to precisely understand its burden to the already weaker health system and underserved population. ${ }^{268} \mathrm{We}$, thus intended to assess a 5-year trend in pre-eclampsia admission, the magnitude of inpatient eclampsia and factors associated with the development of inpatient eclampsia among pre-eclamptic women who gave birth in Woldia General Hospital, a mid-level resource-limited public hospital serving a large catchment area in the northeastern part of Ethiopia.

\section{METHODS}

\section{Study setting and period}

The study was conducted from 8 August 2017 to 10 September 2017 at Woldia General Hospital, Woldia town, Ethiopia. The town is the capital of North Wollo Zone, located in Amhara regional state at $520 \mathrm{~km}$ north of the capital, Addis Ababa. According to the local administration report in 2016, the town had a total population of 75446 of which 37279 were females. This figure did not account population from suburban areas. Regarding the healthcare facility, the town has one public hospital, two public health centres and 12 private pharmacies and five medium-level clinics. At the time of the study, the hospital had 120 beds and 328 employees, of them 20 were doctors (one senior obstetrician), 128 nurses and 21 midwives. It provides outpatient and inpatient services including obstetric and gynaecological care. According to the medical director' statement, the hospital faced many challenges such as lack of drugs, equipment, supporting infrastructure (especially consistent electric power) and trained personnel. A $35 \mathrm{~m}^{2}$ regular patient ward is usually equipped with more than six beds. Until the data collection period, there was no separate room for pre-eclampsia admission as per the standard. In addition, essential services in maternal care such as blood bank cannot be accessed in the hospital compound.

\section{Study design and sampling procedures}

A hospital-based document review was implemented in which a patient's medical file was reviewed sequentially from the time of admission to their discharge (a maximum of 7 days post partum). All pre-eclamptic women who were admitted and gave birth at Woldia General Hospital from 1 September 2011 to 31 August 2016 were included for the review. The year 2011 was selected as it was the year that Health Information Management System was inaugurated at a national level which in turn favoured data collection quality from validation with facility-level database. Pregnant women admitted with pre-eclampsia whose medical file was grossly incomplete; postadmission antepartum and intrapartum maternal death, referral to higher facility before getting birth, and pre-eclamptic women diagnosed with cerebral malaria and seizure disorders were excluded from analysis. The reason to exclude medical records with early maternal death and referrals before they got birth was the fact that nearly $75 \%$ of eclampsia have reported to happen during intrapartum and postpartum combined. Therefore, it was because of the authors' intention to get the actual magnitude of inpatient eclampsia and to incorporate factors interplayed at antenatal, intrapartum and postnatal periods.

\section{Patient and public involvement}

No patients were involved.

\section{Study variables}

The outcome variable was inpatient eclampsia (grouped as Yes/No). The independent variables were sociodemographic factors such as maternal age and place of residence; obstetric factors such as gravidity and antenatal follow-up for current pregnancy; comorbidities; condition at admission; and management-related factors such as time lapsed from admission to commencing different treatments, anti-hypertensive modalities, anti-convulsion modalities and modes of delivery.

\section{Operational definitions}

Inpatient eclampsia was defined in the study as the development of tonic-clonic seizure or coma (a Glasgow Coma Scale score $\leq 8$ lasting $\geq 6$ hours) among admitted preeclamptic women in the absence of reported/diagnosed seizure disorders or cerebral malaria. Patient medical file was labelled incomplete if it failed to mention the outcome variable, or if greater than $20 \%$ of the independent variables were missed. We have used the routine clinical classification of pre-eclampsia as mild and severe. Hence, cases of documented blood pressure of more than $140 / 90 \mathrm{~mm} \mathrm{Hg}$ but less than $160 \mathrm{~mm} \mathrm{Hg}$ systolic or $110 \mathrm{~mm} \mathrm{Hg}$ diastolic with qualitative dipstick proteinuria less than +2 (mild proteinuria) was labelled as mild whereas a persistent systolic blood pressure of $>160 \mathrm{~mm} \mathrm{Hg}$ or diastolic pressure of $>110 \mathrm{~mm} \mathrm{Hg}$ with significant protein excretion of greater than +3 (marked 
proteinuria) or presence of suggestive evidence for end-organ involvement (even without proteinuria) was recorded as severe pre-eclampsia. If pre-eclamptic women reported at least one of these symptoms-headache, visual problem, epigastric pain, platelet count below $100000 / \mathrm{mm}^{3}$ or aspartate aminotransaminase (AST) $>70 \mathrm{IU} / \mathrm{L}-$ the subject was labelled as having signs of endorgan involvement. Comorbidity status for HIV, diabetes mellitus, chronic hypertension and anaemia was assessed as either 'Yes/No' based on patient's self-report or laboratory result. Women with haemoglobin level less than $11 \mathrm{~g} /$ $\mathrm{dL}$ were reported as anaemic and classified as severe $(\mathrm{Hb}$ $<7.0 \mathrm{~g} / \mathrm{dL}$ ), moderate $(\mathrm{Hb} 7.0-9.9 \mathrm{~g} / \mathrm{dL})$ and mild $(\mathrm{Hb}$ $10.0-10.9 \mathrm{~g} / \mathrm{dL}$ ). Time-lapse measurements were taken in hours and categorised based on their mean, median or percentile after checking for its normality.

\section{Data collection tool and quality assurance}

The data were collected using a pre-tested check list to assess sociodemographic variable, medical and obstetrics history, sign and symptoms at presentation, laboratory result, interventions at each department and whether eclampsia happened or not. The data were obtained from admission registration logbooks, medical and nursing care progress notes, delivery registration books, laboratory and drug prescriptions. To maintain data quality, a 3-day intensive training was undertaken to four BSc in midwifery holder data collectors and one supervisor, a clinical midwife (MSc). The checklist has been compared with similar tools that have been used for large-scale studies and pretested on randomly selected patient files from the same institution. Efforts have been made to obtain complete data set by referring different folders and registration books. Besides, there have been scheduled visits by a supervisor to monitor and support the data collectors. Twenty-three errors during data retrieval were detected through double checking and corrections were considered for 16 of them after consulting the respective senior obstetrician and data clerks while the rest were considered as missed data.

\section{Data processing and analysis}

Data were entered and analysed by SPSS V.23 (RRID: SCR_002865). Percentage, frequency distribution, mean and SD were used to describe different variables. Variables such as diastolic blood pressure was checked for their normality and reported using mean and SD. The proportion of pre-eclampsia admission was tested for its yearly trend using Mann-Kendall trend test (Kendall's taub). The effect of each variable on perinatal death was first tested by bivariable logistic regression. Confounding bias imposed by the interdependence nature of independent variables was further controlled by multivariable logistic regression. Model assumptions were assured, associations were tested with $\mathrm{p}$ value less than 0.05 and results were reported by their adjusted odds ratio values along with 95\% CI.

\section{RESULT}

There were 8764 deliveries attended at Woldia General Hospital in the 5-year period of which 248 were diagnosed with pre-eclampsia. Seven medical files were further excluded due to incomplete documentation and maternal death during delivery. Therefore, findings from this study were reported based on 241 reviewed medical documents. The mean maternal age $( \pm \mathrm{SD})$ was $25.73 \pm 4.8$ with the minimum and maximum of 15 and 40 , respectively. More than half (54.4\%) of admissions were from rural areas.

Regarding gravidity status, $138(57.3 \%)$ women were primigravida while 103 (42.7\%) were multigravida, from which only 2 of them had been pregnant for more than five times. Antenatal care utilisation for recent pregnancy was also assessed. Nearly a quarter of the patients had a history of at least one visit at the nearby healthcare delivery points for reason related with their pregnancy. Data have been also extracted to check whether or not patients have known comorbidity with diabetes mellitus, HIV, chronic hypertension and anaemia. Thus, $57(23.7 \%)$ patients were comorbid with at least one of the listed four. The study assessed the patient's condition from the time of admission through the course of their management until they were discharged. In this regard, the mean gestational age (in weeks days) at patient's admission was $37^{+6}( \pm 2+5)$ in which 24 and 42 completed weeks were the minimum and maximum recorded gestational age at admission, respectively. The mean diastolic blood pressure measurement at admission was 105.87 $(+10.58) \mathrm{mm} \mathrm{Hg}$.

Nearly half $(46.9 \%)$ of the patients had at least one subjective manifestation signalling an end-organ involvement of the disease process such as headache, epigastric pain and visual problem. Headache was a frequently mentioned (48.7\%) complaint. Across the course of treatment, initial diagnosis was revised for five patients. Of which four were worsening cases from mild pre-eclampsia to severe and the remaining one was improvement from severe pre-eclampsia to mild pre-eclampsia. Regarding proteinuria, from 227 patients for whom their urine was assessed for proteinuria, $108(47.6 \%)$ of them had $\mathrm{a}+2$ (mild) and $75(33 \%)+3$ (moderate) proteinuria by dipstick (table 1).

\section{Trend of pre-eclampsia}

Across the 5-year period, 241 out of 8764 deliveries $(2.76 \%)$ co-occurred with pre-eclampsia. Majority (224; 92.9\%) of the patients report the onset of sign and symptoms after 34 weeks of their gestation. Of all, 138 (57.3\%) were diagnosed with severe pre-eclampsia, followed by mild pre-eclampsia and superimposed pre-eclampsia on chronic hypertension (100 (41.5\%) and 3 (1.2\%), respectively). From multigravid women for whom their clinical presentation has been reviewed for their previous pregnancies, 81/83 reported their illness as the first ever experience in their childbearing history (figure 1). 
Table 1 Sociodemographic, medical and obstetric characteristics of pre-eclamptic women admitted to Woldia General Hospital from 2011 to 2016

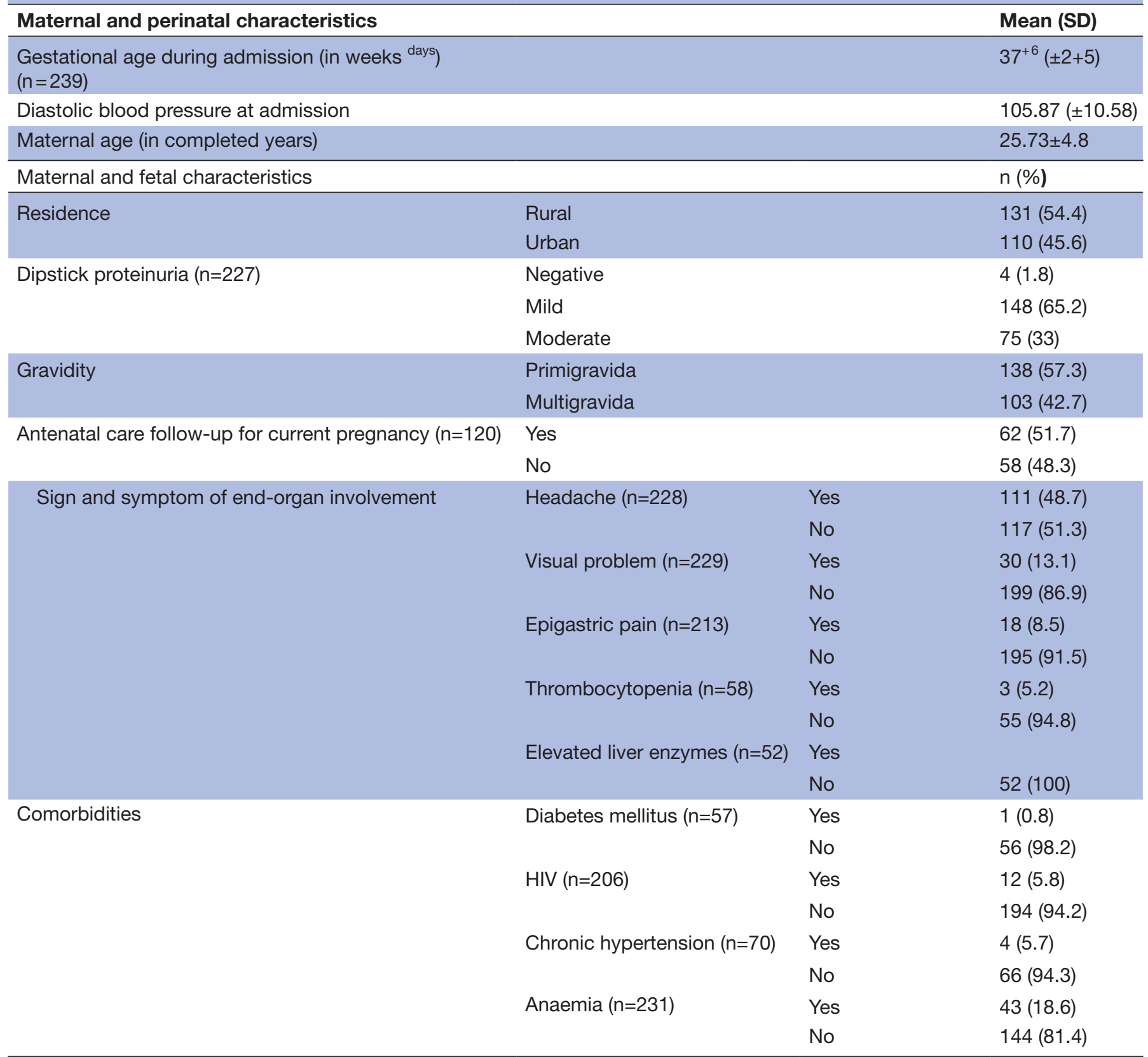

As shown in figure 1, the magnitude showed a marginal decrement through years $(T b)=-0.4, \mathrm{p}=0.035$ whereas the highest caseload (4.4\%) was observed on year 2013/2014.

\section{Magnitude and factors related with inpatient eclampsia}

Out of 241 pre-eclamptic women admitted and delivered through the 5-year period, $17(7.1 \%, 95 \%$ CI $2.7 \%$ to $11.5 \%$ ) of them developed inpatient eclampsia in the form of tonic-clonic seizure $15(88.2 \%)$ and coma $2(11.8 \%)$. This gave the rate of inpatient eclampsia in labour admission 19.6 per 10,000 births. Comparing women's age and development of inpatient eclampsia, the finding showed majority $(39 \%)$ of cases were among the age group of 25-29. More than half $(10 ; 58.8 \%)$ of this complication happened during their antenatal admission period and the rest were happened during labour and deliver (table 2).

Most inpatient eclampsia happened among women diagnosed with severe preeclampsia.

As shown in figure 2, the trend of $\mathrm{MgSO}_{4}$ and diazepam usage tended to run oppositely while extending the use of these anticonvulsants 24 hours post partum slightly increasing through time. However, none of these variables were related with inpatient eclampsia (figure 2).

Bivariate logistic regression was first conducted to test the separate effect of each variable towards the development of inpatient eclampsia with a $\mathrm{p}$ value of less than 


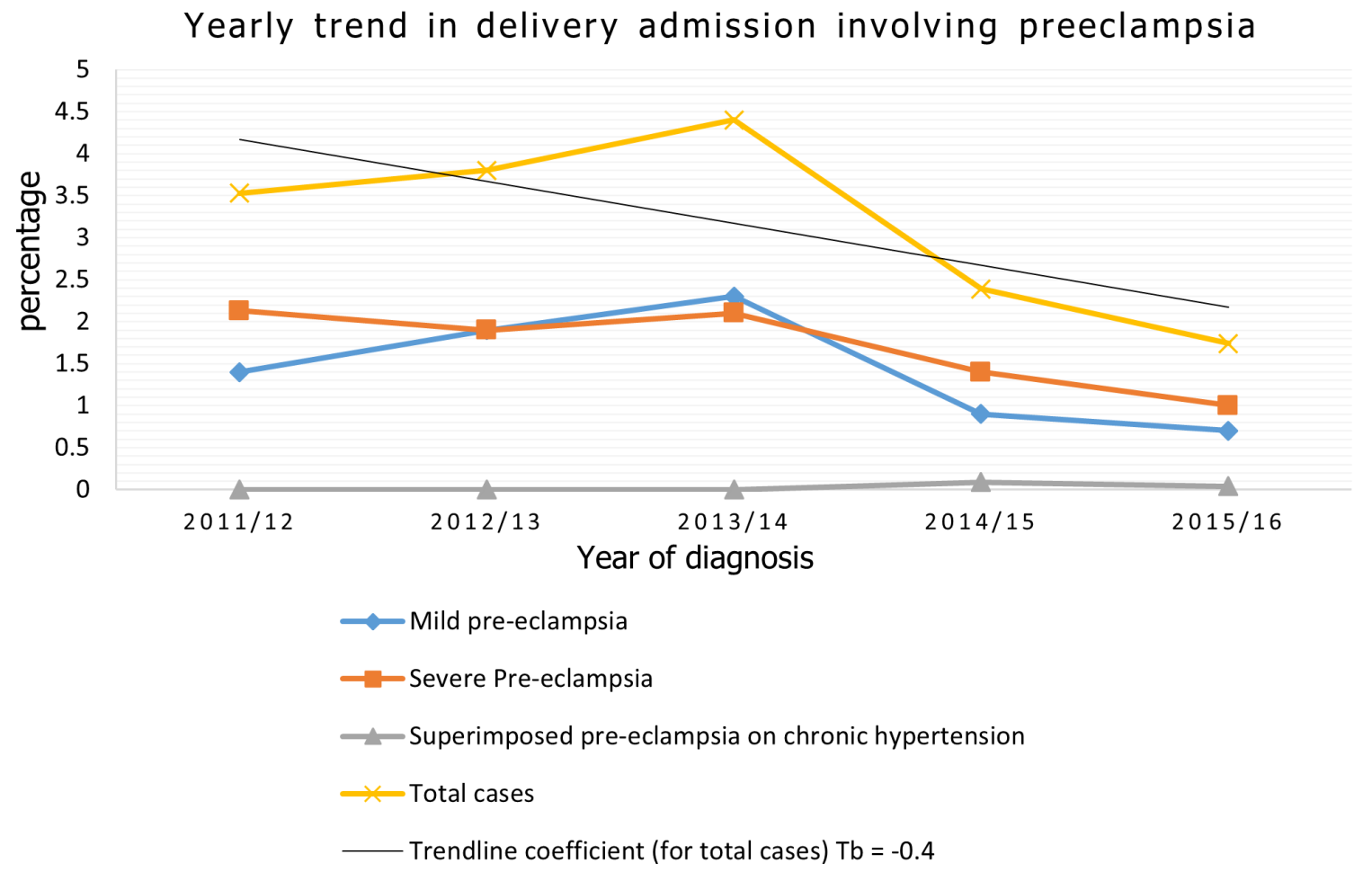

Figure 1 Yearly trend in delivery admission involving pre-eclampsia at Woldia General Hospital from 2011 to 2016.

Table 2 Distribution of some maternal and perinatal variables across types of pre-eclampsia diagnosed at the inpatient department of Woldia General Hospital from 2011 to 2016

\begin{tabular}{|c|c|c|c|c|c|}
\hline & & \multicolumn{2}{|l|}{ Type of pre-eclampsia } & \multirow[b]{2}{*}{ Pearson $\mathrm{X}^{2}$} & \multirow[b]{2}{*}{$P$ value } \\
\hline \multicolumn{2}{|c|}{ Maternal and neonatal characteristics } & $\begin{array}{l}\text { Mild pre-eclampsia n } \\
(\%)\end{array}$ & $\begin{array}{l}\text { Severe pre-eclampsia* } n \\
(\%)\end{array}$ & & \\
\hline \multirow{5}{*}{$\begin{array}{l}\text { Maternal age in } \\
\text { years }\end{array}$} & $15-19$ & $7(31.8)$ & 15 (68.2) & 3.066 & 0.547 \\
\hline & $20-24$ & $34(45.9)$ & $40(54.1)$ & & \\
\hline & $25-29$ & $35(37.2)$ & $59(62.8)$ & & \\
\hline & $30-34$ & $14(41.2)$ & $20(58.8)$ & & \\
\hline & $\geq 35$ & $9(52.9)$ & $8(47.1)$ & & \\
\hline \multirow[t]{2}{*}{ Gravidity } & Primigravida & $57(41.3)$ & $81(58.7)$ & 0.007 & 0.934 \\
\hline & Multigravida & $42(40.8)$ & $61(59.2)$ & & \\
\hline \multirow[t]{2}{*}{ Inpatient eclampsia } & Yes & $2(11.8)$ & $15(88.2)$ & 6.494 & $0.011 \dagger$ \\
\hline & No & $97(43.3)$ & $127(56.7)$ & & \\
\hline \multirow{2}{*}{$\begin{array}{l}\text { Mode of delivery } \\
(\mathrm{n}=240)\end{array}$} & Vaginal delivery & $91(44.4)$ & $114(55.6)$ & 5.720 & $0.017 \dagger$ \\
\hline & Caesarean section & $8(22.9)$ & $27(77.1)$ & & \\
\hline \multirow{3}{*}{$\begin{array}{l}\text { Gestational age at } \\
\text { birth } \\
(n=240)\end{array}$} & Less than 37 weeks & $21(30.0)$ & $49(70.0)$ & 5.563 & 0.062 \\
\hline & $37-40$ weeks & $68(45.0)$ & $83(55.0)$ & & \\
\hline & Beyond 40 weeks & $10(52.6)$ & $9(47.4)$ & & \\
\hline \multirow{3}{*}{$\begin{array}{l}\text { Birth weight in } \\
\text { grams }(n=237)\end{array}$} & less than $1500 \mathrm{~g}$ & $3(30.0)$ & $7(70.0)$ & 10.534 & $580.005 \dagger$ \\
\hline & $1500-2500 \mathrm{~g}$ & 29 (29.9) & $68(70.1)$ & & \\
\hline & $2500-4000 \mathrm{~g}$ & 66 (50.8) & 64 (49.2) & & \\
\hline
\end{tabular}

*Superimposed pre-eclampsia on chronic hypertension $(n=3)$ were merged with severe pre-eclampsia.

†Statistically significant association. 


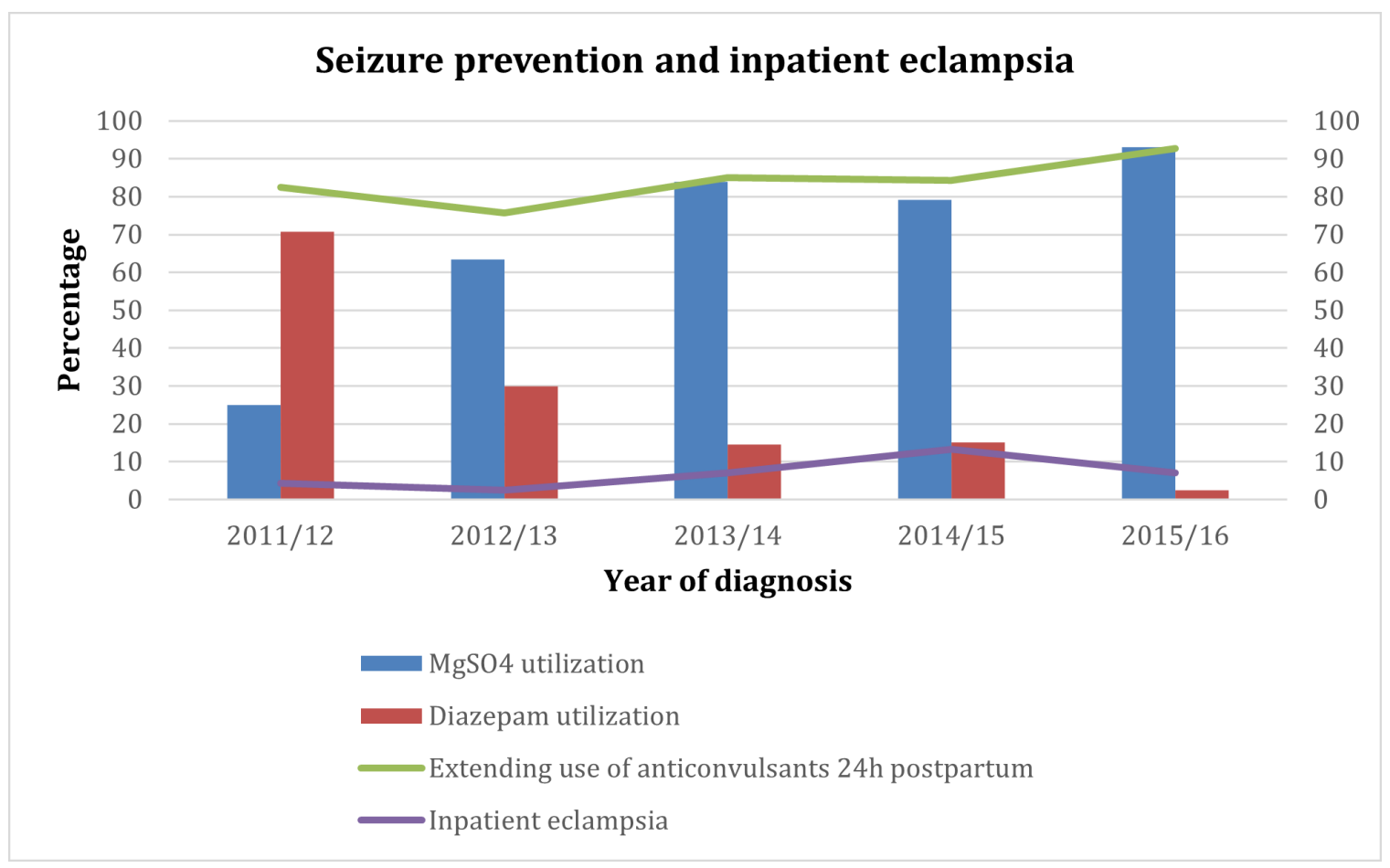

Figure 2 Magnitude of inpatient eclampsia and trend of seizure prevention measures for inpatient pre-eclamptic women in Woldia General Hospital from 2011 to 2016.

0.05. Being multigravida (crude OR (COR) $0.266,95 \%$ CI 0.074 to 0.950$)$, diagnosed with severe pre-eclampsia (COR 5.728, 95\% CI 1.280 to 25.644) and spontaneous onset of labour (COR 5.468, 95\% CI 1.707 to 17.520) were associated with inpatient eclampsia. Multivariable analysis was done to control confounding effect and analyse the independent effect of each variables. After ensuring the model fitness, gravidity and onset of labour demonstrated statistically significant association with inpatient eclampsia. From the result, multigravida women were about six times less likely to develop inpatient eclampsia compared with primigravid women (AOR 0.154, 95\% CI 0.029 to 0.831$)$. Similarly, the occurrence of inpatient eclampsia was five times higher among women who had spontaneous onset of labour than those who have been induced (AOR 5.628, 95\% CI 1.1247 to 9.401) (table 3).

\section{DISCUSSION}

The study tried to answer the yearly trend of preeclampsia-related admission, the magnitude of inpatient eclampsia and factors contributing to inpatient eclampsia. In our setup, the 5-year overall magnitude of pre-eclampsia admission was $2.76 \%$ which showed similarity with studies conducted in other public hospitals in Ethiopia, namely, Dilla University Referral Hospital $(2.23 \%)$ and Mettu Karl Referral Hospital (2.4\%). ${ }^{9} 10$ The finding also showed only a slight difference from a $3.3 \%$ overall incidence of pre-eclampsia from a nationwide study in Australia, ${ }^{11}$ a $4 \%$ prevalence of pre-eclampsia/ eclampsia from a large-scale hospital-based multi-country study ${ }^{8}$ and a reported range of $1.4 \%-4.0 \%$ prevalence of pre-eclampsia from an international comparative study. ${ }^{12}$ However, it was less than $8.4 \%$ which was reported from a study conducted in Dessie Referral Hospital, Ethiopia. ${ }^{13}$ The possible reason for this discrepancy might be that, on the latter study, data were collected from women who visited an antenatal clinic where patients receiving care on the outpatient department could raise the figure. Similarly, a finding from our study might be much lower than 6\%-14\% estimated prevalence of pre-eclampsia worldwide as multiple factors could raise the worldwide estimation of pre-eclampsia including a composite report from the community, outpatient and inpatient department, increased antenatal care coverage and favourable healthcare-seeking behaviour of women from developed nations.

Studies from different parts of the world reported that the rate of pre-eclampsia and other hypertensive pregnancy disorders tended to be increasing through time. ${ }^{14-17}$ To the contrary, despite increasing trend of preeclampsia risk factors such as pre-pregnancy overweight and obesity, diabetes, multiple births and advanced maternal age at first pregnancy, findings from large-scale studies ${ }^{1112} 18$ showed a decreasing trend of pre-eclampsia as it was observed in our study. For example, a secondary analysis conducted in Australia showed $50 \%$ reduction on the incidence of pre-eclampsia from $4.6 \%$ to $2.3 \%$ over an 8-year period. ${ }^{11}$ This trend was nearly similar with our study in which the highest case load was $4.4 \%$ and the lowest was $1.76 \%$. One of the potential reasons for this downward trend could be increasing coverage of antenatal care (ANC). In Ethiopia, from 2000 to 2016, ANC 
Table 3 Factors associated with inpatient eclampsia among pre-eclamptic women admitted and gave birth from 2011 to 2016: results from the bivariable and multivariable logistic regression analysis

\begin{tabular}{|c|c|c|c|c|c|}
\hline Variable & & COR $(95 \% \mathrm{Cl})$ & $P$ value & AOR $(95 \% \mathrm{Cl})$ & $P$ value \\
\hline \multirow[t]{2}{*}{ Resident } & Urban & 1 & 0.532 & 1 & 0.341 \\
\hline & Rural & $0.730(0.272$ to 1.961$)$ & & 0.536 (0.149 to 1.933$)$ & \\
\hline \multirow[t]{2}{*}{ Gravidity } & Primigravida & 1 & 0.042 & 1 & $0.030^{*}$ \\
\hline & Multigravida & 0.266 (0.074 to 0.950$)$ & & 0.154 (0.029 to 0.831$)$ & \\
\hline \multirow{2}{*}{$\begin{array}{l}\text { Diastolic blood pressure at } \\
\text { admission }\end{array}$} & $<110 \mathrm{~mm} \mathrm{Hg}$ & 1 & 0.209 & 1 & 0.787 \\
\hline & $\geq 110 \mathrm{~mm} \mathrm{Hg}$ & 1.934 (0.691 to 5.411$)$ & & 1.257 (0.239 to 6.608$)$ & \\
\hline \multirow{2}{*}{$\begin{array}{l}\text { Evidence suggestive for } \\
\text { an end-organ involvement }\end{array}$} & No & 1 & 0.630 & 1 & 0.270 \\
\hline & Yes & 1.275 (0.475 to 3.424$)$ & & 0.466 (0.120 to 1.809$)$ & \\
\hline \multirow[t]{2}{*}{ Type of pre-eclampsia } & Mild & 1 & 0.022 & 1 & 0.676 \\
\hline & Severe & 5.728 (1.280 to 25.644$)$ & & $1.510(0.726$ to 13.221$)$ & \\
\hline \multirow{2}{*}{$\begin{array}{l}\text { Time lapse from admission } \\
\text { to start anticonvulsant } \dagger\end{array}$} & Less than 1 hour & 1 & 0.988 & 1 & 0.957 \\
\hline & More than 1 hour & 0.990 (0.258 to 3.802$)$ & & $1.050(0.182$ to 6.052$)$ & \\
\hline \multirow[t]{3}{*}{ Anticonvulsants used } & Diazepam & 1 & 0.905 & 1 & \\
\hline & Magnesium sulfate & 0.936 (0.317 to 2.759$)$ & & 0.811 (0.223 to 2.439$)$ & 0.672 \\
\hline & No anticonvulsant & & & & \\
\hline \multirow{2}{*}{$\begin{array}{l}\text { Anticonvulsant usage } \\
\text { extended } 24 \text { hours post } \\
\text { partum }(n=210)\end{array}$} & No & 1 & 0.270 & 1 & 0.133 \\
\hline & Yes & 3.180 (0.047 to 24.456$)$ & & 0.159 (0.014 to 1.750$)$ & \\
\hline \multirow[t]{2}{*}{ Onset of labour $(n=239)$} & Induced & 1 & 0.004 & 1 & $0.025^{*}$ \\
\hline & Spontaneous & 5.468 (1.707 to 17.520$)$ & & 5.628 (1.1247 to 9.401$)$ & \\
\hline \multirow[t]{3}{*}{ Qualitative proteinuria } & No proteinuria & 1 & & 1 & \\
\hline & Mild proteinuria & $1.200(0.419$ to 3.438$)$ & 0.734 & 1.115 (0.765 to 2.066$)$ & 0.487 \\
\hline & Moderate proteinuria & 2.812 (0.098 to 6.739$)$ & 0.847 & $0.436(0.107$ to 1.776$)$ & 0.247 \\
\hline
\end{tabular}

*Statistically significance association.

†Analysis was done for severe pre-eclamptic women.

AOR, adjusted odds ratio; COR, crude odds ratio.

coverage has been increased from $26.7 \%$ to $62.4 \% .{ }^{19}$ This may come with an improvement in the early identification of cases over time and hence the initiation of medication at earlier gestations to maintain blood pressure control at acceptable limits. Earlier treatments could also have resulted in more women receiving a diagnosis of gestational hypertension rather than pre-eclampsia. In addition, the national treatment guideline recommends mild pre-eclamptic patients to be followed on the outpatient setting. This group of patients may seek medical attention and subsequently gave birth to other health care institutions specially in a the private sector.

Studies from a similar set of population have showed that a larger proportion of patients with pre-eclampsia were diagnosed as severe pre-eclampsia ${ }^{92021}$ as a similar finding was observed in our study. Regarding patients' age group, most of the patients were aged around mid-20's with narrow SD as it has been reported from studies. ${ }^{9} 101314$ Such finding shared similarity with ours as the mean and standard deviation $( \pm \mathrm{SD})$ of patient age in completed years was $25.73 \pm 4.8$.
Regarding the magnitude of inpatient eclampsia among pre-eclamptic women, the finding from our setup $(7.1 \%)$ was slightly lower than findings from $\mathrm{Nepal}^{21}(8.27 \%)^{21}$, but its rate during labour admissions (19.6/10 000 births) doubles the rate of inpatient eclampsia in Australia (8.6/10 000 births). ${ }^{11}$ The justification for this difference could be possibly reflected on the difference in quality of care between developed and developing nations including availability and proper usage of anticonvulsants, ratio of skilled healthcare professionals to patients, capacity of hospitals and the healthcare system as a whole. The rate of inpatient eclampsia in Europe which has been reported as low as 2-3 cases per 10000 births $^{22} 23$ and a disproportionally higher rate in developing countries (16-69 per 10000 births) could support this justification. ${ }^{24}$

In multivariate analysis, the findings from this study showed that being multigravida was associated with lower inpatient eclampsia compared with the primigravida counterparts. In support of this, findings from large population-based studies in Australia and USA showed the increased risk of eclampsia among primigravida 
women than multiparous. ${ }^{11} 25$ The possible justification for such difference may be due to a difference in the degree of immune maladaptation between the two groups. Difference in immunological responses to the semi-allogenic fetus is among the speculations suggested for the apparent risk difference of pre-eclampsia between primiparous and multiparous women. Such difference that favours multiparous women may still partially protect them from developing severe complications such as eclampsia after having pre-eclampsia. Regarding onset of labour, similar with the finding from a multi-centre randomised controlled trial targeted to compare labour induction versus expectant management on maternal outcome including eclampsia, ${ }^{26} 27$ our finding also showed that labour induction has a protective association with inpatient eclampsia. This difference may not directly related with onset of labour. Rather it could be due to the time-lapse difference and the risk it causes to wait for spontaneous onset of labour and induction of labour. Clinicians may tend to expect spontaneous onset of labour given improvements in blood pressure, proteinuria and other laboratory findings. This may increase the admission time and the likelihood of eclampsia among patients. This finding was in support of the WHO statement on pre-eclampsia case management as vigilant examination, aggressive treatment and timely delivery are advised for women with pre-eclampsia irrespective of their clinical features. Our analysis demonstrated that neither the type of anticonvulsant nor its duration of use related with the occurrence of inpatient eclampsia, and such finding was also stated from a secondary analysis of a randomised controlled trial undertaken in Sub-Sahara African countries as a neutral association was reported between magnesium sulfate availability and the rate of eclampsia across study sites. ${ }^{28}$

\section{Limitation}

Missed data and challenge to identify other possible causes of seizure except for cerebral malaria and pre-existing seizure disorders could affect the precision of findings from our study. Despite its impact on patients with preeclampsia, psychosocial health and targeted interventions have been overlooked by healthcare professionals, thus none of such variables were included in our analysis. Comparison between admitted non-pre-eclamptic women with pre-eclamptic counterparts on common parameters could give better reference for the findings. This study only analysed data from pre-eclamptic women. In addition, factors affecting hypertension during pregnancy such as chronic kidney disease, antiphospholipid syndrome, systemic lupus erythematosus and type of conception were not assessed in the study.

\section{CONCLUSION}

In the study setting, the overall magnitude of pre-eclampsia admission was comparable with the global average, but its rate showed marginal decrement from year 2011 to 2016 despite the increasing trend of pre-eclampsia exposing risk factors in the general population. High rate of inpatient eclampsia especially during the antenatal admission period may indicate undertreatment which speaks for further study and corrective actions. Waiting for spontaneous onset of labour could increase the risk of developing inpatient eclampsia whereas neither type of anticonvulsant nor duration of their usage has made significant association.

Acknowledgements We would like to thank Woldia University for its financial support. We also extend our gratitude to Woldia General Hospital Administrative officials, Health Management Information System officer and staff working at the hospital's archive for their unreserved effort to make the data collection more effective.

Contributors KGT and MLE conceived the research idea, supervised the project, wrote the manuscript draft, data analysis and participated through the review process. MAG, AGN and ETK participated in the study design, data analysis, result interpretation and manuscript writing. All the authors read and approved the final manuscript.

Funding The study was funded by Woldia University with grant number WURCSVP/209/2017.

Disclaimer The funding body did not have any role in the study design, data collection, analysis and interpretation of data, and in writing the manuscript.

Competing interests None declared.

Patient and public involvement Patients and/or the public were not involved in the design, or conduct, or reporting, or dissemination plans of this research.

Patient consent for publication Not required.

Ethics approval Ethical approval letter was obtained from the institutional review board of Woldia University. Permission was also granted from the hospital administrative office to access the archive for patients' medical records. Anonymisation and quantitative presentation of findings ascertained patients' confidentiality. Written or oral consent from patients was not applicable.

Provenance and peer review Not commissioned; externally peer reviewed.

Data availability statement Data are available on reasonable request. All necessary data can be available from the corresponding author on request.

Open access This is an open access article distributed in accordance with the Creative Commons Attribution Non Commercial (CC BY-NC 4.0) license, which permits others to distribute, remix, adapt, build upon this work non-commercially, and license their derivative works on different terms, provided the original work is properly cited, appropriate credit is given, any changes made indicated, and the use is non-commercial. See: http://creativecommons.org/licenses/by-nc/4.0/.

ORCID iD

Kenean Getaneh Tlaye http://orcid.org/0000-0001-8464-4345

\section{REFERENCES}

1 Hypertension in pregnancy. Report of the American College of Obstetricians and Gynecologists' Task Force on Hypertension in Pregnancy. Obstet Gynecol 2013;122:1121-31.

2 Abalos E, Cuesta C, Grosso AL, et al. Global and regional estimates of preeclampsia and eclampsia: a systematic review. Eur J Obstet Gynecol Reprod Biol 2013;170:1-7.

3 Hutcheon JA, Lisonkova S, Joseph KS. Epidemiology of preeclampsia and the other hypertensive disorders of pregnancy. Best Pract Res Clin Obstet Gynaecol 2011;25:391-403.

4 Kathryn R, Mabry-Hernandez FI, Ngo-Metzger Q. Delivery hospitalizations involving preeclampsia and eclampsia, 2005-2014. Rockville (MD: Agency for Healthcare Research and Quality, 2017.

5 Priso EB, Njamen TN, Tchente CN, et al. Trend in admissions, clinica features and outcome of preeclampsia and eclampsia as seen from the intensive care unit of the Douala General Hospital, Cameroon. Pan Afr Med J 2015;21:103.

6 Roberts CL, Ford JB, Algert CS, et al. Population-based trends in pregnancy hypertension and pre-eclampsia: an international comparative study. BMJ Open 2011;1:e000101. 
7 Duley L. The global impact of pre-eclampsia and eclampsia. Semin Perinatol 2009;33:130-7.

8 Bilano VL, Ota E, Ganchimeg T, et al. Risk factors of pre-eclampsia/ eclampsia and its adverse outcomes in low- and middle-income countries: a WHO secondary analysis. PLoS One 2014;9:e91198.

9 Seyom E, Abera M, Tesfaye M, et al. Maternal and fetal outcome of pregnancy related hypertension in Mettu Karl Referral Hospital, Ethiopia. J Ovarian Res 2015;8:10.

10 Vata PK, Chauhan NM, Nallathambi A, et al. Assessment of prevalence of preeclampsia from Dilla region of Ethiopia. BMC Res Notes 2015;8:6.

11 Thornton C, Dahlen H, Korda A, et al. The incidence of preeclampsia and eclampsia and associated maternal mortality in Australia from population-linked datasets: 2000-2008. Am J Obstet Gynecol 2013;208:5.

12 Roberts CL, Ford JB, Algert CS, et al. Population-based trends in pregnancy hypertension and pre-eclampsia: an international comparative study. BMJ Open 2011;1:9.

13 Tessema GA, Tekeste A, Ayele TA. Preeclampsia and associated factors among pregnant women attending antenatal care in Dessie Referral Hospital, northeast Ethiopia: a hospital-based study. BMC Pregnancy Childbirth 2015;15:7.

14 Wagnew M, Dessalegn M, Worku A, et al. Trends of preeclampsia/ eclampsia and maternal and neonatal outcomes among women delivering in Addis Ababa selected government hospitals, Ethiopia: a retrospective cross-sectional study. Pan Afr Med J 2016;25:12.

15 Chan T-F, Tung Y-C, Wang S-H, et al. Trends in the incidence of preeclampsia and eclampsia in Taiwan between 1998 and 2010. Taiwan J Obstet Gynecol 2015;54:270-4.

16 Breathett K, Muhlestein D, Foraker R, et al. Differences in preeclampsia rates between African American and Caucasian women: trends from the national hospital discharge survey. $J$ Womens Health 2014;23:8.

17 Fox R, Kitt J, Leeson P, et al. Preeclampsia: risk factors, diagnosis, management, and the cardiovascular impact on the offspring. J Clin Med 2019;8:1625.
18 Liu C-M, Cheng P-J, Chang S-D. Maternal complications and perinatal outcomes associated with gestational hypertension and severe preeclampsia in Taiwanese women. J Formos Med Assoc 2008;107:10.

19 ICF Central Statistical Agency (CSA) [Ethiopia]. Ethiopia Demographic and Health Survey 2016: Key Indicators Report. Addis Ababa, Ethiopia, and Rockville, Maryland, USA: CSA and ICF, 2016.

20 Segni ZWH, Woldie M. Hpertensive disorders of pregnancy in Jimma University Specialized Hospital. Ethiop J Health Sci 2010;21:147-54.

21 Acharya S, Pal MN. Maternal and perinatal complications in preeclampsia. J Univ Coll Med Sci 2013;3:21-5.

22 Subramaniam V. Seasonal variation in the incidence of preeclampsia and eclampsia in tropical climatic conditions. BMC Womens Health 2007;7:18.

23 Kullberg G, Lindeberg S, Hanson U. Eclampsia in Sweden. Hypertens Pregnancy 2002;21:13-21.

24 Altman D, Carroli G, Duley L, et al. Do women with preeclampsia, and their babies, benefit from magnesium sulphate? The Magpie Trial: a randomised placebo-controlled trial. Lancet 2002;359:1877-90.

25 Anna E, Hansen CS, Littman AJ. Risk factors for eclampsia: a population-based study in Washington State, 1987-2007. Am J Obstet Gynecol 2011;205:e1-7.

26 van der Tuuk K, van der Tuuk K, Koopmans CM, et al. Should cervical favourability play a role in the decision for labour induction in gestational hypertension or mild pre-eclampsia at term? An exploratory analysis of the HYPITAT trial. BJOG 2012;119:1123-30.

27 Koopmans CM, Bijlenga D, Aarnoudse JG, et al. Induction of labour versus expectant monitoring in women with pregnancy induced hypertension or mild preeclampsia at term: the HYPITAT trial. BMC Pregnancy Childbirth 2007;7:14.

28 Vousden N, Lawley E, Seed PT, et al. Incidence of eclampsia and related complications across 10 low- and middle-resource geographical regions: secondary analysis of a cluster randomised controlled trial. PLoS Med 2019;16:e1002775. 